\title{
The Psychological Distress, Subjective Burden and Affiliate Stigma among Caregivers of People with Mental IIIness in Amanuel Specialized Mental Hospital
}

\author{
Kahsay Weldeslasie Hailemariam \\ Department of Psychology, College of Social Sciences and Languages, Mekelle University, Mekelle, Ethiopia
}

Email address:

kasweld@gmail.com,kaspsyc@yahoo.com

To cite this article:

Kahsay Weldeslasie Hailemariam. The Psychological Distress, Subjective Burden and Affiliate Stigma among Caregivers of People with Mental Illness in Amanuel Specialized Mental Hospital. American Journal of Applied Psychology. Vol. 4, No. 2, 2015, pp. 35-49. doi: 10.11648/j.ajap.20150402.13

\begin{abstract}
The researcher employed mixed approach with cross sectional research design in order to collect comprehensive data from caregivers of people with mental illness at a time. Most of the caregivers developed from moderate to severe psychological distress, subjective burden and stigma. Most of the participant's variables don't have statistically significant difference in experiencing of psychological distress and subjective burden on caregivers. But, patients' type of disorder brings statistically significant difference in creating psychological distress and subjective burden on caregivers $(\mathrm{t}=2.28$, df $=173$, $\mathrm{p}<0.05$ and $\mathrm{t}=2.64$, df, $=173, \mathrm{p}<0.05)$ respectively. In relation to the care giving burden, average mean score of caregivers of people with psychotic disorder were found to be 46.83 and the average mean score of participants who have been giving care for the mood patients were found to be 43.92. With regards to the psychological distress, the average mean score of participants who give care for psychotic patients and mood patients were found to be 27.58 and 25.66 respectively. There is also significant relationship between care giving burden and psychological distress $(r=0.34, p<0.01)$, care giving burden and affiliate stigma $(r=0.335, p<0.01)$, psychological distress and affiliate stigma $(r=0.23, p<0.01)$, time spent on care giving and care giving burden $(\mathrm{r}=-0.205, \mathrm{p}<0.01)$. Generally, having family members with mental illness exposed caregiver to have psychological distress, subjective burden and affiliate stigma.
\end{abstract}

Keywords: Psychological Distress, Subjective Burden, Affiliate Stigma, Caregivers

\section{Introduction}

Mental health is more than the mere lack of mental disorders. It includes subjective well-being, perceived selfefficacy, autonomy, competence, intergenerational dependence and recognition of the ability to realize one's intellectual and emotional potential. It is a state of well-being whereby individuals recognize their abilities, are able to cope with the normal stresses of life, work productively and fruitfully, and make contributions to their communities, [1]. In addition to this, mental health is about enhancing competencies of individuals and communities and enabling them to achieve their self-determined goals. Such individuals function well in society, are accepted within a group, and are generally satisfied in their lives, [1].

In contrast, mental illness is a disorder, which is characterized by disturbances in persons' thought, emotion, behavior and relationship. In other word, mental illness is a health problem that significantly affects how a person feels, thinks, behaves, and interacts with other people, [1].

Throughout history, people have held quite different views of the problems that we considered to be mental disorder. During ancient period, the cause of mental disorder is attributed to the disfavor of the gods or the mischief of demons, [2]. This mental illness was also treated through traditional beliefs and practices.

Family members who living in Hong Kong [3], with traditional Chinese culture considers mental illness as biologically attributed. As a result, the society stigmatizes individuals who have mental illness in their family. Comparing with the Western countries, this misunderstanding towards severe mental illnesses related to faulty biological functioning, personal misconduct and spiritual beliefs and the resulting social stigma to the illness may result in less favorable social support and more intense guilt feelings and burden in care giving of relatives with 
schizophrenia. The findings may have social implications in that traditional cultural values and social stigma attached to mental illness is an issue of great concern to family caregivers, [4]. To enhance high quality of community care, it is important to increase social support and reduce social stigma towards mental illness, [4].

In most cultural orientation, family members are often seen as principal source of support and important partners in the rehabilitation of the mentally ill person. In developing countries with recent estimates indicating that between $1 / 3$ and $2 / 3$ of persons with mental illness currently reside with family members, [5]. In Nigeria and other most developing countries, the percentage was more likely to be higher, [5]. Relatives of the patient have to bear the major burden of care and this may result an increase in the families' daily responsibilities and sources of stress at a time when they are also dealing with the uncertainty and stigma of chronic psychiatric. This may possibly leads to psychopathology in the caregivers of patients, [6].

In the Western countries, the term 'family burden' has been frequently used in research to describe the extent to which family life is affecting. From the 1970 s to 1980 s, the adverse consequences of psychiatric disorders for family caregivers, known as 'caregiver burden', have been studied for determining the feasibility of discharging patients into community or to refine the concept of care giving and its underlying structure and content, [7]. In a comprehensive conceptual framework for both objective and subjective caregivers' burden [7]; objective burden refers to the observable consequences on family's physical and psychological well-being due to the symptoms and behavior of patients, where as subjective burden relates to caregivers' feeling of distress and other psychological reactions towards care giving experiences. However, the focus of this study was on the subjective dimension of family's burden of care giving only.

Caregivers of people with mental illness [8] stigmatized by their neighbors because, they consider the illness is only given to them by the punishing hands of the God. These make caregivers to feel distressed and burdened in their care giving experiences. Caregivers may encounter with, stigma (social exclusion), emotional burden, physical burden, and economic burden due to their care giving experiences, [7].

Studies on caregivers have documented numerous adverse effects of care giving for mentally ill family members on their quality of life, such as time lost from work, financial loss, limited time for leisure and social life, as well as adverse health effects such as elevated symptoms [9] of distress, feelings of stigmatization, poorer self-rated health, chronic medical conditions, greater use of tranquilizers and anti-depressants and increased risk of medical hospitalization.

Objective and subjective burdens are the dimensions of burden that can be highly affected families of the mentally ill individuals [10]. In addition, there are five dimensions of [11] "objective" burden: These are, disturbed family relations provoked by mental disorders, financial costs linked to these difficulties, poor social performance of the person suffering from mental disorder, support for daily living given to the person, and problem behavior exhibited by the person. However, these objective variables were not treated equally as the subjective burdens in this study.

As far as the subjective dimension is concerned, researchers have linked it to the emotional cost to the family resulting from the mental disorder, for example, [11] feeling trapped, being confined to the house, tending to become isolated, feeling responsible or under obligation to the person, feeling of having bad seed in the family and having emotional reactions toward the person's behavior. The subjective dimension has also included various interpretations and has been used interchangeably with the concepts of distress and stress, [11]. Subjective burden [12] is the more personal dissatisfaction, apprehension, tension and other internal discomfort as a result of being the family member of the mentally ill person. It is $[9,14]$, possible that more personal and more subtle considerations, such as the preoccupation with son's or daughter's future may cause more emotional distress, especially for the older parents, [15]. The feeling of obligation or preoccupation with the person's well-being has been investigated among adults caring for elderly parents losing autonomy, [16].

The World Health organization moreover disclosed the burdens that the mentally ill family members and the surrounding community face. Economic costs, losing social involvement, stigma and discrimination are the common burdens of caregivers, [1]. The issue of stigma pervaded caregivers' accounts and quality of life in general. The secrecy about mental illness and caregivers' reluctance towards seeking help was often explained as being in response to the potential stigma that comes from the social environment, [17].

Furthermore, millions of caregivers of people with mentally illness are struggling to cope with the social consequences of the problems or threats, which are both from intra-family and inter-family (community). These threats involve social exclusion, care giving burden, blame, stereotypes, stigma and psychological distress in general, [18].

In recent decades [19], various conceptualizations of stigma have been put forth by researchers to understand the complex and multi-leveled effects of stigma on caregivers' mental health. Stigma is referred to as a set of prejudicial attitudes, stereotypes, discriminatory behaviors and biased social structures endorsed [19] by sizeable social groups about discredited subgroups. It includes the processes of labeling, separation, stereotyping, status loss, emotional reactions and discrimination in power situations, [20].

Caregivers of people with mental illness may perceive greater sense of burden and strain in their care giving practices because stigma might have distorted their attitude towards the care-recipients and affect their relationships. Whereas, affiliate stigma refers to the more general affect, cognitions and behavioral reactions as a result of being a close associate with people having stigmatized condition. Subjective burden refers more specifically to caregivers' 
subjective experience and psychological status as a result of providing care to individuals with mental illness, [12]. Previous findings conducted focus groups and interviews on family members and caregivers and they come up with the negative side of care giving experiences. They conclude that, caregivers were stigmatized because of their association they have with the mentally ill person, [8].

Although most studies focused on the negative aspects of care giving and found care giving responsibilities to incur emotional strain on caregivers [21], several studies also pointed out the gratifying or positive aspects of care giving. Care giving was found to be related to personal growth and maturity, better tolerance, strengthened family ties and expanded social networks among the caregivers, [22]. As stigma may influence the way caregivers perceive their relationship with the mentally ill persons and their care giving experience, it is important to account for affiliate stigma in understanding the negative and positive aspects of care giving, [22].

Caregivers are one of the key advocacy groups for recognition of needs, in terms of support and services, for mentally ill persons. Comparing to caregivers of typically developing children, a predictor for morbidity of mental health problems (depression and anxiety) in relatives of individuals with mental illness has been caregiver burden, [13]. As patients' age increases and become adults, new sets of care giving challenges are more likely to happen. Individuals with mental illness are living longer, meaning their caregivers are taking on care giving at an even older age, [13]. It is thus necessary to understand the caregivers' experiences; especially possible obstacles to their care giving experiences, such as stigma and burden.

Previous findings reported that, stigma as the only pain of mentally ill persons. They didn't acknowledge the caregivers' distress, burden and social exclusion from the society. Therefore, this study addressed whether caregivers are emotionally, physically, economically and socially affected like the mentally ill person. Even though, some research findings were recognize the family distress and burden but this study tried to quantify how much it is severe in the Ethiopian culture. In addition to this, the researcher also tried to indicate health professionals to incorporate families' problem in to their intervention program simultaneously with their mentally ill relatives.

The importance of considering psychological distresses among caregivers of people with mental illness is an acceptable issue in the domain of the helping professions such as clinical psychology, social work, counseling psychology, and nursing, in order to understand the impact of the illness on the life of the caregivers and their mentally ill members as well as to provide necessary support.

Some research findings $[22,23]$ also stated the difference in the experience of distress and burden between sexes. Mothers are highly distressed and burdened than anyone who associates with the mentally ill person,[24]. Therefore, the justification behind of conducting this research was, to give due attention to the caregivers rather than sticking only on the patients, to see how much caregivers are facing with care giving burden, to see the role of sex, age, religion, level of income, family size, educational level, etc. on experiencing of burden and distress, to find out whether care giving is promising or curs to the caregivers, to reach at sound conclusions based on caregivers' socio-demographic information, lastly, to indicate concerned individuals who are working in the helping professions to incorporate this issue into their intervention programs.

\section{Methods and Design of the Study}

This study was employ both quantitative and qualitative research method (mixed approach) with cross sectional research design so as to quantify the variables by using different statistical packages as well as to assess the subjective experience and burden of caregivers. The quantitative method may help to get accurate information about the caregivers who experienced psychological distress and subjective burden. In addition to the above reasons, quantitative research method is very important to clearly indicate how much the problem was significant and it also avoids hasty ways of giving conclusions. However, it doesn't mean that quantitative research method has not any limitation. Participants may fill the questionnaire carelessly; it is difficult to address caregivers' subjective experience and burden by using questionnaire only. Therefore, the researcher solved these limitations by using qualitative instrument like semi-structured interview.

\subsection{Research Site}

This study was conducted in Amanuel Specialized Mental Hospital, Addis Ababa the capital city of Ethiopia. The reason for focusing on this area was due to the availability of the target population in the area. In the hospital, there are different wards that individuals can access inpatient and outpatient services. Among these, schizophrenia, mood, drug addiction, forensic, neurotic and geriatric wards are presented in the hospital. However, all these wards were not included in this study. This is because; the researcher needs to address the majority problem of the subjects. Therefore, this study was only focused on the caregivers of psychotic and mood patients who attend the mental health of their family member in the inpatient and outpatient services.

Previously, psychiatric services were given only by foreign professionals working at the hospital and at the clinic in St. Paul's hospital which is found in Addis Ababa, Ethiopia. Currently, services are provided by more than 70 centres throughout the country by trained psychiatric nurses. The number of psychiatrists also increased after starting postgraduate training in the country. According to the data collected from the hospital, currently there are more than 30 psychiatrists in the country making psychiatrist population ratio, one psychiatrist serving about three million people. The country has 53 psychiatric outpatient facilities and 6 inpatient service delivery institutions. All the psychiatric centres give outpatient services. However, inpatient service is provided 
mainly at Amanuel, Specialized Mental Hospital for civilians and at Armed Forces Hospital for the Ethiopian army, [1].

\subsection{Population and Sampling}

The estimated numbers of caregivers who visit the hospital in order to give care for their mentally ill relatives were almost 350 individuals per day from the mood and psychotic wards only. From this population, a researcher selected 50\% (175) caregivers using Simple Random Sampling Technique. This sampling technique is assumed to be reduced bias and subjectivity and to make good conclusions based on the given population to the rest of caregivers in the hospital.

\subsection{Variables of the Study}

In this research different dependent and independent variables were assessed.

Dependent Variables: Caregivers' Psychological Distress and Subjective Burden.

Independent Variables: Affiliate stigma, sex, age, type of relationship with the patient, patients' type of illness, family size and time spent on care giving, level of monthly income, religion and educational level were among the independent variables.

\subsection{Pilot Testing}

For checking the reliability of the instruments, the researcher distributed the questionnaire to 50 caregivers. However, only 38 participants were return back the paper to the researcher. The benefit [25] of piloting for creating opportunity to the modification of research design, research instruments and cost break dawn; time and researcher security is very important issue. For its validity, it was checked by research experts. All scales were achieved excellent internal reliability.

\subsection{Consideration of Ethical Issues}

To protect the confidentiality and privacy of the participants, the proposal was submitted with 3 copies to the research ethical approval committee of the hospital. After carefully checked the ethical issues of the study by the committee, the researcher got an ethical clearance and assistance from the hospital community. Voluntariness and informed consent of participants was clearly stated in the questionnaire.

\subsection{Data Collection Procedures}

By the help of different standardized instruments and semi structured interview, information gathered from the participants who were attended the mental health of their patients in the hospital by the help of research assistants. Before starting to administer the questionnaire to the participants, orientations were given to the data collectors in relation to the ways how to administer the questionnaire to the participants. Having collected the data from the participants, incomplete items were avoided from the questionnaire.

\subsection{Methods of Data Analysis}

This research was analyzed quantitatively and qualitatively so as to infer to other populations and to address the subjective experiences of the participants. The following statistical packages were employed by the help of SPSS $17^{\text {th }}$ version. Among these, percentage, t-test, regression, one way ANOVA, and correlation were employed.

\section{Results}

\subsection{Socio-Demographic Information of Respondents}

Table 1. Demographic Information of Caregivers $(n=175)$

\begin{tabular}{|c|c|c|c|}
\hline Variables & Categories & $\mathbf{N}$ & Total \\
\hline \multirow{2}{*}{ Sex } & Male & 95 & \multirow{2}{*}{175} \\
\hline & Female & 80 & \\
\hline \multirow{4}{*}{ Religion } & Orthodox & 91 & \multirow{4}{*}{175} \\
\hline & Muslim & 52 & \\
\hline & Protestant & 18 & \\
\hline & Catholic & 14 & \\
\hline \multirow{3}{*}{ Marital status } & Married & 82 & \multirow{3}{*}{175} \\
\hline & Divorced & 34 & \\
\hline & Widowed & 20 & \\
\hline \multirow{4}{*}{ Relationship with the patient } & Mother & 31 & \multirow{4}{*}{175} \\
\hline & Father & 26 & \\
\hline & Brother/sister & 81 & \\
\hline & Others & 37 & \\
\hline \multirow{3}{*}{ Academic level } & Illiterate & 45 & \multirow{3}{*}{175} \\
\hline & $9-12$ grade & 60 & \\
\hline & Above 12 grade & 33 & \\
\hline \multirow{5}{*}{ Monthly income } & Below 500 birr & 49 & \multirow{5}{*}{175} \\
\hline & $501-1000$ birr & 51 & \\
\hline & $1001-1500$ birr & 17 & \\
\hline & $1501-2000$ birr & 31 & \\
\hline & Above 2000 birr & 27 & \\
\hline
\end{tabular}


As demonstrated in table 1 , out of the total 175 participants, $95(54.29 \%)$ were males while the rest 80 $(45.71 \%)$ were females. In addition, the table shows that most participants 91 (52\%) were followers of orthodox religion followed by Muslim religion followers 52 (29.71\%), and the remaining two were followers of protestant 18 $(10.29 \%)$ and catholic religion followers, $14(8 \%)$.

Furthermore, the table shows that, 31 (17.71\%) participants were mothers, $26(14.86 \%)$ were fathers and the rest two were brothers/sisters $81(46.29 \%)$ and others 37 $(21.14 \%)$ respectively. Participants of this study have different academic levels, 45 (25.71\%) participants were illiterates, 37 (21.14\%) participants were from 1-8 grades, and the remaining $60(34.29 \%)$ were from $9-12$ and 33 $(18.86 \%)$ were above 12 grade. In addition to this, participants who have monthly income of below 500 birr were $49(28 \%)$, those who have monthly income of 5011000 birr were 51 (29.14\%), participants who have monthly income of 1001 - 1500 birr were $17(9.71 \%)$ and the remaining two were those who have monthly income of 1501 - 2000 birr 31 (17.71\%) and above 2000 birr 27 (15.43\%).

Table 2. Respondents' Care giving Burden, Psychological Distress and Affiliate Stigma Severity Level

\begin{tabular}{|c|c|c|c|c|c|c|c|}
\hline \multirow[t]{2}{*}{ Levels } & \multicolumn{2}{|c|}{ Care giving Burden } & \multicolumn{2}{|c|}{ Psychological Distress } & \multirow[t]{2}{*}{ Levels } & \multicolumn{2}{|c|}{ Affiliate Stigma } \\
\hline & $\mathrm{N}$ & $\%$ & $\mathrm{~N}$ & $\%$ & & $\mathrm{~N}$ & $\%$ \\
\hline Normal & 0 & 0 & 0 & 0 & Low & 0 & 0 \\
\hline Mini./low & 1 & 0.57 & 5 & 2.86 & Moderate & 1 & 0.57 \\
\hline High/severe & 118 & 67.43 & 42 & 24 & Very high & 91 & 52 \\
\hline Total & 175 & 100 & 175 & 100 & & 175 & 100 \\
\hline
\end{tabular}

As table 2 indicates, most participants 118 (67.43\%) who have been giving care to mentally ill individuals have experienced high or severe level of care giving burden. Besides, 56(32\%) of respondents were experiencing moderate level of care giving burden. None of them was found to have normal level of care giving burden. When we see the level of psychological distress, the majority $128(73.14 \%)$ participants reported that, they were suffering from moderate level of psychological distress. The rest 42(24\%) participants were experiencing high/severe psychological distress. When we come to the level of affiliate stigma of caregivers, $83(47.43 \%)$ participants were reported as they have high level of feeling of affiliate stigma. The majority $91(52 \%)$ participants were experiencing very high feeling of affiliate stigma.

Table 3. Sex Difference on Caregivers' Care Giving Burden

\begin{tabular}{lllllll}
\hline Variable & Sex & N & Mean & SD. & df & T \\
\hline Care giving & Male & 80 & 44.67 & 8.06 & 173 & 1.06 \\
Burden & Female & 95 & 45.86 & 6.81 & & \\
\hline
\end{tabular}

$\alpha=0.05$

Table 3 implies that, there was no statistically significant difference between male and female participants $(t=1.06, \mathrm{df}$ $=173, \mathrm{p}>0.05)$. This is to mean, the average score between the two sexes were found to be nearly the same.

Table 4. Sex Difference on Caregivers' Psychological Distress

\begin{tabular}{lll|l|l|l|ll}
\hline Variable & Sex & N & Mean & SD. & df & T & Sig \\
Psychological & Male & 80 & 26.89 & 6.12 & 173 & 0.66 & 0.52 \\
Distress & Female & 95 & 26.33 & 5.21 & & & \\
\hline
\end{tabular}

Table 4 shows that, there is no statistically significant difference in psychological distress between male and female participants $(\mathrm{t}=0.66, \mathrm{df}=173, \mathrm{p}>0.05)$. Of course, the mean score of females in psychological distress is almost equal to male participants who have been giving care to mentally ill individuals.

Table 5. Caregivers' Burden across the Type of Patients' Disorder

\begin{tabular}{lllllll}
\hline Variable & Type of disorders & N & Mean & SD. & df & T \\
\hline Care giving & mood & 91 & 43.92 & 7.73 & 173 & $2.64^{*}$ \\
Burden & psychotic & 84 & 46.83 & 6.79 & & \\
\hline
\end{tabular}

$* \alpha=0.05$

As table 5 shows, there is statistically significant difference in care giving burden between participants who have been given care to mentally ill patients with mood disorder and psychotics $(\mathrm{t}=2.64$, df, $=173, \mathrm{p}<0.05)$. Here the mean score of respondents who have been giving care to patients with mood disorder was found to be 43.92 which is less than those who were giving care to psychotic patients (46.83). 
Table 6. Caregivers' Psychological Distress across the Type of Patients' Disorder

\begin{tabular}{llllllll}
\hline Variable & Type of disorder & N & Mean & SD. & df & T & Sig \\
\hline Psychological & Mood & 91 & 25.66 & 5.62 & 173 & $2.28^{*}$ & 0.024 \\
Distress & Psychotic & 84 & 27.58 & 5.52 & & & \\
\hline
\end{tabular}

$* \alpha=0.05$

Table 6 indicates that, there is statistically significant difference in care giving burden between participants who have been given care to mentally ill patients with mood disorder and psychotics $(\mathrm{t}=2.28, \mathrm{df}=173, \mathrm{p}<0.05)$. The mean score of participants who have been giving care to patients with mood disorder was found to be (25.66) which is less than the mean score of those who were giving care to patients with psychotic disorder (27.58).

Table 7. Caregivers' Care Giving Burden in Relation to Their Marital Status

\begin{tabular}{lllll}
\hline Variables & Marital status & N & Mean & SD \\
\hline \multirow{3}{*}{ Care giving } & Married & 82 & 45.59 & 7.12 \\
Burden & Single & 39 & 44.72 & 7.19 \\
& Divorced & 34 & 45.94 & 8.72 \\
Total & Widowed & 20 & 44.20 & 6.96 \\
\hline
\end{tabular}

Table 7 shows, how caregivers feel care giving burden and psychological distress with respect to care giving burden, the average score of married and single respondents were found to be 45.59 and 44.72 respectively. In addition, as table 7 shows, the mean score of care giving burden of divorced and widowed respondents were found to be 45.94 and 44.20 respectively.

Table 8. Psychological Distress in Relation to Caregivers' Marital Status

\begin{tabular}{lllll}
\hline Variables & Marital status & N & Mean & SD \\
\hline \multirow{4}{*}{ Psychological } & Married & 82 & 26.09 & 6.18 \\
Distress & Single & 39 & 26.15 & 4.42 \\
& Divorced & 34 & 26.74 & 5.34 \\
Total & Widowed & 20 & 29.15 & 5.60 \\
\hline
\end{tabular}

As table 8 illustrated that, the average score of married and single participants were found to be 26.09 and 26.15 respectively. Whereas the average score of divorced and widowed participants were found to be 26.74 and 29.15 respectively.

Table 9. Care Giving Burden across Marital Status of Caregivers of People with Mental Illness

\begin{tabular}{llllll}
\hline Variables & SS & df & MS & F & Sig. \\
\hline Between group & 56.36 & 3 & 18.79 & 0.34 & 0.79 \\
Within group & 9511.72 & 171 & 55.62 & & \\
Total & 9568.08 & 174 & & & \\
\hline
\end{tabular}

$\alpha=0.05$

Table 9 shows that caregivers' marital status does not have statistically significant difference in experiencing feeling of subjective burden across the different categories of marital status $(\mathrm{F}=1.69, \mathrm{df}=3, \mathrm{p}>0.05)$. This is to mean that, whether someone is married, single, divorced or widowed, he/she doesn't feel the care giving burden in different ways.

Table 10. Psychological Distress across Caregivers' Marital Status of People with Mental Illness

\begin{tabular}{llllll}
\hline Variables & SS & df & MS & F & Sig. \\
\hline Between group & 159.08 & 3 & 53.03 & 1.69 & 0.17 \\
Within group & 5375.46 & 171 & 31.44 & & \\
Total & 5534.55 & 174 & & & \\
\hline
\end{tabular}

$\alpha=0.05$

Table 10 shows that, caregivers' marital status doesn't have any statistically significant difference in experiencing feeling of psychological distress on caregivers $(\mathrm{F}=1.69, \mathrm{df}=3$, $\mathrm{p}>0.05)$. Relatively speaking, caregivers feel the psychological distress of care giving similarly even if they are found at the different categories of marital status.

Table 11. Caregivers' Burden in Relation to Their Educational Levels

\begin{tabular}{lllll}
\hline Variables & Edu. Level & N & Mean & SD \\
\hline \multirow{3}{*}{ Care giving } & Illiterate & 45 & 44.09 & 8.07 \\
Burden & $1-8$ grade & 37 & 45.32 & 7.82 \\
& $9-12$ grade & 60 & 46.63 & 6.76 \\
Total & Above 12 grade & 33 & 44.60 & 7.11 \\
\hline
\end{tabular}

Table 11 indicates that how caregivers who are found at the different educational levels sense care giving burden and psychological distress. With regards to care giving burden, the average score of illiterate and 1-8 grade respondents were found to be 44.09 and 45.32 respectively. In addition, as the table shows the mean score of care giving burden of $9-12$ grades and above 12 grade respondents were found to be 46.63 and 44.60 respectively.

Table 12. Psychological Distress in Relation to Caregivers' Educational Levels

\begin{tabular}{lllll}
\hline Variable & Edu. Level & N & Mean & SD \\
\hline & Illiterate & 45 & 27.36 & 6.46 \\
Psychological & 1 - 8 grade & 37 & 26.95 & 5.78 \\
Distress & $9-12$ grade & 60 & 26.28 & 5.38 \\
& Above 12 grade & 33 & 25.67 & 4.75 \\
Total & & 175 & & \\
\hline
\end{tabular}

As table 12 shows, in respect to the psychological distress of caregivers the average score of illiterate and 1-8 grade participants were found to be 27.36 and 26.95 respectively. Whereas the average mean scores of grade $9-12$ grade and above 12 grade participants were found to be 26.28 and 25.67 respectively. 
Table 13. Care giving Burden across Educational Level of Caregivers of People with Mental Illness

\begin{tabular}{llllll}
\hline Variables & SS & df & MS & F & Sig. \\
\hline Between group & 188.52 & 3 & 62.84 & 1.15 & 0.33 \\
Within group & 9379.57 & 171 & 54.85 & & \\
Total & 9568.08 & 174 & & & \\
\hline
\end{tabular}

$\alpha=0.05$

As table 13 indicates, there is no significant difference in developing care giving burden with different educational levels of caregivers $(\mathrm{F}=1.15, \mathrm{df}=3, \mathrm{p}>0.05)$. Here, the mean score in table 8 also shows the mean scores of respondents with various educational levels on care giving burden are nearly similar.

Table 14. Psychological Distress across Educational Level of Caregivers of People with Mental Illness

\begin{tabular}{llllll}
\hline Variables & SS & df & MS & F & Sig. \\
\hline Between group & 64.83 & 3 & 21.61 & 0.68 & 0.57 \\
Within group & 5469.72 & 171 & 31.99 & & \\
Total & 5534.55 & 174 & & & \\
\hline
\end{tabular}

$\alpha=0.05$

Table 14 shows that, caregivers' educational level does not bring statistically significant difference on caregivers' psychological distress $(\mathrm{F}=0.068, \mathrm{df}=3, \mathrm{p}>0.05)$. Caregivers who were at the different educational levels, relatively sense care giving burden in similar way.

Table 15. Caregivers' Burden in Relation to Their Monthly Income

\begin{tabular}{lllll}
\hline Variables & Monthly income & N & Mean & SD \\
\hline \multirow{4}{*}{ Care giving } & Below 500 birr & 49 & 45.04 & 7.21 \\
Burden & 501 - 1000 birr & 51 & 45.76 & 8.00 \\
& $1001-1500$ birr & 17 & 47.53 & 6.33 \\
& Above 2000 birr & 27 & 43.33 & 7.49 \\
Total & & 175 & & \\
\hline
\end{tabular}

Table 15 shows, how caregivers who have different monthly income feel care giving burden and psychological distress in relation to care giving burden, the average mean score of participants who have monthly income of below 500 birr and 501-1000 birr participants were found to be 45.04 and 45.76 respectively. Furthermore, the average mean score of participants who have monthly income of $1001-1500$ birr and $1501-2000$ birr participants were found to be 47.53 and 45.55 respectively, and the mean score of participants who have monthly income of above 2000 were found to be 43.33 .

Table 16. Psychological Distress in Relation to Caregivers' Monthly Income

\begin{tabular}{lllll}
\hline Variable & Monthly income & N & Mean & SD \\
\hline & Below 500 birr & 49 & 26.67 & 5.52 \\
Psychological & $501-1000$ birr & 51 & 27.08 & 6.11 \\
Distress & $1001-1500$ birr & 17 & 27.71 & 4.66 \\
& $1501-2000$ birr & 31 & 25.16 & 6.32 \\
Total & Above 2000 birr & 27 & 26.41 & 4.65 \\
\hline
\end{tabular}

As table 16 shows, with regard to the psychological distress of caregivers, the average mean score of participants who have monthly income of below 500 birr and $501-1000$ birr participants were found to be 26.67 and 27.08 respectively. Whereas, the average mean score of participants who have monthly income of $1001-1500$ birr and $1501-$ 2000 birr were found to be 27.71 and 25.16 respectively. The average mean score of respondents who have monthly income of above 2000 birr were found to be 26.41 .

Table 17. Care Giving Burden across Monthly Income of Caregivers of People with Mental Illness

\begin{tabular}{llllll}
\hline Variables & SS & df & MS & F & Sig. \\
\hline Between group & 205.07 & 4 & 51.27 & 0.93 & 0.45 \\
Within group & 9363.01 & 170 & 55.08 & & \\
Total & 9568.08 & 174 & & & \\
\hline
\end{tabular}

$\alpha=0.05$

Table 17 indicates that, the monthly income of caregivers does not show meaningful mean difference in developing feeling of burden on caregivers of people with mental illness $(\mathrm{F}=0.93, \mathrm{df}=205.07, \mathrm{p}>0.05)$. This means that, whether someone has high or low monthly income, he or she feels the burden relatively in the same way.

Table 18. Psychological Distress across Monthly Income of Caregivers of People with Mental Illness

\begin{tabular}{llllll}
\hline Variables & SS & df & MS & F & Sig. \\
\hline Between group & 97.85 & 4 & 24.46 & 0.77 & 0.55 \\
Within group & 5436.70 & 170 & 31.98 & & \\
Total & 5534.55 & 174 & & & \\
\hline
\end{tabular}

$\alpha=0.05$

Table 18 implies, Caregivers' monthly income doesn't have significant difference in developing psychological distress due to the association or caring to the patient with mental illness $(\mathrm{F}=0.77, \mathrm{df}=4, \mathrm{p}>0.05)$. Generally, where ever caregivers placed on the different category of monthly income, but this category does not bring statistically significant mean difference or change on caregivers' psychological distress.

Table 19. Caregivers'Burden in Relation to Their Relationship with the Patient

\begin{tabular}{lllll}
\hline Variables & Relationship & N & Mean & SD \\
\hline \multirow{3}{*}{ Care giving } & Mother & 26 & 42.92 & 7.04 \\
Burden & Father & 31 & 44.55 & 7.77 \\
& Brother/sister & 81 & 41.37 & 6.08 \\
Total & Others & 37 & 46.16 & 7.38 \\
\hline
\end{tabular}

As table 19 shows, the care giving burden and psychological distress across the different relatives of the mentally ill individuals. With respect to the care giving burden, the average mean scores of mothers and fathers were found to be 42.92 and 44.55 respectively and the average mean scores of brother/sister and others were found to be 41.37 and 46.16 respectively. 
Table 20. Caregivers' Psychological Distress in Relation to Their Relationship with the Patient

\begin{tabular}{lllll}
\hline Variable & Relationship & N & Mean & SD \\
\hline \multirow{3}{*}{ Psychological } & Mother & 26 & 26.08 & 5.74 \\
Distress & Father & 31 & 27.09 & 7.39 \\
& Brother/sister & 81 & 27.84 & 5.17 \\
Total & Others & 37 & 25.95 & 4.99 \\
\hline
\end{tabular}

Table 20 indicates, the psychological distress of caregivers and the average mean scores. The average mean scores of mothers and fathers were found to be 26.08 and 27.09 respectively. Whereas, the average mean scores of brother/sister and others were found to be 27.84 and 25.95 respectively. As the table indicates that, the means scores across the types of relationship with the patient are more or less similar.

Table 21. Care Giving Burden across Caregivers' Type of Relationship they have with the Patient

\begin{tabular}{llllll}
\hline Variables & SS & df & MS & F & Sig. \\
\hline Between group & 233.90 & 3 & 77.99 & 1.43 & 0.24 \\
Within group & 9334.20 & 171 & 54.58 & & \\
Total & 9569.10 & 174 & & & \\
\hline
\end{tabular}

$\alpha=0.05$
Table 21 implies that there is no significant mean difference among the types of relationship with the patient in experiencing of subjective burden on caregivers of people with mental illness $(\mathrm{F}=1.43, \mathrm{df}=3, \mathrm{p}>0.05)$. It means, being a father, mother, sister/brother or other kind relationship with the patient, does not make significant difference on care giving burden. Caregivers more or less similarly sense whatever the burden imposed from their patient.

Table 22. Psychological Distress across Caregivers' Type of Relationship they have with the Patient

\begin{tabular}{llllll}
\hline Variables & SS & df & MS & F & Sig. \\
\hline Between group & 35.19 & 3 & 11.73 & 0.37 & 0.78 \\
Within group & 5499.00 & 171 & 32.16 & & \\
Total & 5534.19 & 174 & & & \\
\hline
\end{tabular}

$\alpha=0.05$

Table 22 shows no statistically significant difference among the type of relationship with the patient in developing psychological distress $(\mathrm{F}=0.37$, df $=3, \mathrm{p}>0.05)$. Relatively speaking, caregivers equally share for the psychological distress of care giving regardless of the type of relationship they have with the patient.

Table 23. The correlation between age, family size, year of care giving, affiliate stigma, caregiver burden and psychological distress

\begin{tabular}{llllll}
\hline Variables & Family size & Year of care giving & Affiliate stigma & Care giving burden & Psychological distress \\
\hline Age of respondents & -.099 & .142 & -.084 & -.032 & .007 \\
Family size & -.100 & -.013 & $-.205^{* *}$ & -.142 \\
Years of care giving & & -.130 & $.335^{* *}$ & -.101 \\
Affiliate stigma & & & $.233^{* *}$ \\
Care giving burden & & & $.341^{* *}$ \\
\hline
\end{tabular}

**. Correlation is significant at the 0.01 level (2-tailed).

Table 23 indicates, there is significant, weak and negative relationship between number of years on care giving and care giving burden of the participants $(\mathrm{r}=-0.21, \mathrm{P}<0.01)$. This indicates that as year of care giving increases the feeling of burden on caregivers decrease.

There is also found that significant, weak and positive correlation between affiliate stigma and care giving burden, affiliate stigma and psychological distress $(r=0.34$ and 0.23 , $\mathrm{p}<0.01)$ respectively. The higher the caregivers' perceived stigma in care giving, the more the care giving burden and psychological distress they faced. In addition to this, relatively high, positive and statistically significant relationship were found between care giving burden and psychological distress $(\mathrm{r}=0.341, \mathrm{p}<0.01)$. This implies that, as care giving burden of the caregivers increases, psychological distress also increase and vice versa. In contrast, as the above table shows the remaining variables have no significant correlation.

Table 24. The Prediction of Psychological Distress by Care Giving Burden

\begin{tabular}{lllll}
\hline Variable & $\mathbf{R}$ & $\mathbf{R}^{2}$ & Constant & Sig. \\
\hline Care giving burden & 0.34 & 0.116 & 14.84 & 0.00 \\
\hline
\end{tabular}

As table 24 shows, $11.60 \%$ of psychological distress of participants were found to be due to the care giving burden $\left(\mathrm{r}=.34, \mathrm{r}^{2}=0.116\right.$ or $\left.11.60 \%, \mathrm{p}<0.05\right)$. This is to mean, care giving burden predicts $11.60 \%$ of psychological distress.

Table 25. The Prediction of Psychological Distress by Affiliate Stigma

\begin{tabular}{lllll}
\hline Variable & $\mathbf{R}$ & $\mathbf{R}^{\mathbf{2}}$ & Constant & Sig. \\
\hline Affiliate stigma & 0.23 & 0.054 & 15.06 & 0.002 \\
\hline
\end{tabular}

Table 25 shows, $5.4 \%$ of psychological distress of respondents were found to be because of affiliate stigma $\left(\mathrm{r}=0.23, \mathrm{r}^{2}=0.054\right.$ or $\left.5.4 \%, \mathrm{p}<0.05\right)$. In other word, affiliate stigma predicts $5.4 \%$ of psychological distress of participants.

\subsection{Qualitative Data which collected Through Interview from Purposively Selected Participants}

Twelve caregivers were purposively interviewed to collect the qualitative data that can support the quantitative information. Out of the 12 participants 6 of them were males and the remaining 6 were females. Those participants were freely expressed what they feel about their care giving experiences. Caregivers were reported their burden and distress as stated below.

Relatives have faced with numerous and long lasting 
caring demands due to the complex needs and problems especially of the chronic ill family members. They reported that numerous challenges of care giving for mentally ill family member on the caregivers' quality of life, such as absence from work, financial incapability, feeling of inferiority, limited time for leisure and other social issues, as well as adverse health effects such as elevated symptoms of distress and depression.

Caregivers explained that as they are increasingly responsible for providing basic care giving services to their mentally ill family members. The adverse effects of care giving have been found across different angle of settings including: family, health, work, and recreation. Caregivers of people with mental illness have also been shown to report impaired personal, social and vocational role performance as a result of their care giving responsibilities. These strains on caregivers may contribute to overall poor quality of life. Most of the participants reported that, they have responsibilities to watch their relatives with mental illness, to provide foods, to keep their hygiene, to take bedroom and toilet. In short, patients could do nothing without the help of their caregivers. Caregivers lost different social life that other age mates can get.

There is high frequency of caregivers who feel that the patient depends on them, also they don't have enough money to take care of the patient, they feel so burdened taking care of the patient, they don't have enough time for themselves and feel angry when they are around their relatives. A high proportion of caregivers $n=8(66.67 \%)$ needs to leave the care of the relative to someone else, they also feel embarrassed over their relative's behavior, they feel that their relative asks for more help than he/she needs, they feel strained, they feel that they should do more for their relative, they feel stressed to take care of the patient and trying to meet other responsibilities, they feel that they don't have as much privacy as they would like. Also these relatives feel that the patient seems to expect them to take care of him/her as if they were the only person who can do that, they also afraid of patient's future and finally they feel that they have lost control of their own life due to the patient's illness.

Caregivers were generally unhappy with their life in general, due to the reason that the mental health status of their close relatives. Caregivers were reported that, caring for patients with mental illness has an impact on their mental well-being. Common consequences include feelings of uncertainty, shame, guilt, and anger. The most extensively investigated psychological outcome associated with caring for patients with severe mental illness is depression. Depression is serious risk factor for caregivers that are associated with poor subjective quality of life and other adverse outcomes such as functional incompetence. One of the most consistently found predictors of caregiver's depression as well as overall distress was the severity level of the patient's symptoms.

Caregivers reported that, they always prefer to leave from this world, because they never get anything that can enjoy their life in this earth. God is created them to spent bad and worst life in this world; they don't get meaning of survival in this world. Whatever bad things in this world are always visited them, they always think about what the future life of their patient.

Caregivers often have feelings of stigmatized or socially isolated because of the psychiatric illness of their relatives. Families have to bear the major burden of care and this has resulted to increase in the families' daily responsibilities and sources of stress at a time when they are also dealing with the uncertainty and stigma of chronic psychiatric illness in close relatives. Participants explained that as they feel unsure of how 'normal' people will identify or receive them and become constantly self-conscious and calculating about what impression they are making.

More than $67.43 \%$ (118) of participants were reported that, they always feel inferior due to their mentally ill relatives. They always embarrassed by the behavior of their patients when their friends are with them. People in their neighbors stigmatized them not to have marriage relationship. This is because; people in their neighbor consider the illness as it transfers hereditary from parents to children. In addition to this they never go to different social gatherings because, they consider others are talking at them due to the mentally ill close relatives.

\section{Discussion}

The researcher comes up with the negative effects of care giving for mentally ill family members. Most of the caregivers were developed from moderate $n=128$ (73.14\%) to severe psychological distress $n=42(24 \%)$ as a result of their care giving experiences.

According to Novak and Guest [26] Scoring manual: The scale that measures the mental health status of caregivers has 45 total scores and its cutoff point is stated below;

$0=$ Caregivers are found in a normal circumstance

$1-15=$ Caregivers have low psychological distress

$16-30=$ Caregivers have moderate psychological distress

$31-45=$ Caregivers have severe psychological distress

Therefore, participants in this finding were found mostly in the moderate and severe psychological distress. From this result, the researcher concluded that, having family member who has mental illness at home or hospital make caregivers to have psychological distress. This is similar to previous findings.

Disruption of personal and family life, social isolation and constraints [27] on physical mobility were found to be the common aspects of caregivers' experiences. Caring for persons diagnosed with mental illness is often exposed to be physically and mentally exhausting and time consuming impacts on the lives of the caregivers and their families. Clearly speaking, the work of caring involves great deal of emotional labor [28] that can, in some instances, lead to feelings of ambivalence towards those who are cared for and put caregivers under great deal of stress on personal relationships.

Furthermore, the illness whether physical or mental has 
inevitable impacts on the lives of others in multiple ways. Caregivers have responsibilities [29] of managing the signs and symptoms of their relatives as well as they are expected to provide treatment continuously. Caregivers can involve great deal of physical and emotional work, personal sacrifice, and adjusting to changed circumstances and altered conceptions of self and others, [27]. Most studies focused on the negative aspects of care giving and found care giving responsibilities to incur emotional strain on caregivers, [21].

However, some research findings also reported the promising aspects of care giving. Care giving was found to be related to personal enhancement, better forbearance, strengthened family cohesion and lingering social networks among the caregivers, [22]. Overcoming difficulties in care giving can provide family caregivers with sense of inner strength and happiness,[16]. In fact, almost all families can identify strengths that they have developed as a result of coping with their relative's mental illness,[23].

Due to the challenges of mental illness, family members tend to first seek support from other family members and close friends, and then turn to others who have similar experiences, [30]. The involvement of other family members in care giving may validate the caregiver's experience and provide mutually supportive environment that encourages personal growth while meeting the challenges in coping with mental illness. Family members may also seek support from other families who are facing similar problems. Participating in support group reduces social loneliness and provides opportunities for family members to grow gaining knowledge about mental illness, learning advocacy skills, and becoming more [31] confident in their capacity for care giving. The relatives of the mentally ill persons may be source of support to the patient through the provision of companionship or instrumental help,[32]. Helping each other in the relationship may validate the caregiver's efforts and promote positive understandings of their care giving experience.

Participants in the interview explained that, care giving for the mentally ill individuals is just considering oneself as a mentally ill. This is to mean participants were suffering from different social and psychological angles in their life. Due to their mentally ill relatives, they spent very challenging and dark life. Most of participants explained that, having family members who have mental illness makes to feel frustrated. Caregivers feel inferiority due to their mentally ill relatives and people in their neighbors stigmatized them in marriage and other social relationships. This is because people consider the illness as genetically inherited. In addition to this, caregivers restrict themselves from different social gatherings in order to avoid stigma and discrimination. They always feel self-conscious by their patient's behavior when they are with other people in their locality.

The researcher found that, caregivers of people with mental illness were suffering from mostly high $\mathrm{n}=118$ $(67.43 \%)$ and moderate $n=56(32 \%)$ care giving burden. The burdens were emotional burden, economic burden, physical burden and other social burdens. This is similar with previous findings. The Caregivers' Burden Inventory was previously applied to 150 primary caregivers from outpatient clinics in Taiwan and was shown to have excellent psychometric properties, [33]. Subjective burden was assessed in five areas: emotional burden, social burden, timedependent burden, developmental burden and physical burden. This scale has 63 total score and its cutoff point is;

$0=$ Families have no burden

$1-21=$ Families have minimum burden

$22-42=$ Families have moderate burden

$43-63=$ Families have high burden

The scale was achieved excellent internal consistencies $($ Cronbach's alpha $=0.90)$. This scale was developed by, Novak and Guest [34]. According to the above cut-off points, participants in this finding have mostly found from moderate to high burden due to their care giving practices.

There greater experience of emotional, physical and economic burden in families of mentally ill individuals who [35] have patients with mental illness supposes personal, social and economic challenge to the caregivers. Relatives have important restriction of their free time and private life, as well as negative effects inside of the family and worries about patient's future, [22]. Other studies also show significant caregivers restriction and worries about the future patients' life, [36].

The same thing is explained in the interview by caregivers that as they increasingly responsible for providing basic care giving services to their mentally ill family member. The adverse effects of care giving have been found across spectrum of settings including: family, health, work, and recreation, [37]. Caregivers of people with mental illness have also been shown to report impaired personal, social and vocational role performance as a result of their care giving responsibilities. These strains on caregivers may contribute to overall low quality of life.

As per the report of the caregivers, stigma is the major psychological strain that makes them to feel inferior, hopeless, and low self-esteem. Like the previous research findings, this research also come up with the negative impact of stigma on caregivers' quality of life.

The Affiliate Stigma Scale (ASS) has total score of 84 and was achieved excellent internal validity in the previous studies. The cutoff point of this scale is;

$1-21=$ Very low stigma

$22-42=$ Moderate stigma

$43-63=$ High stigma

$64-84=$ Very high stigma.

The overall scale with its scoring manual was developed by Novak and Guest [34] and it has an excellent internal consistency (Cronbach's alpha $=0.94)$. In the current study, the scale also achieved excellent reliability of Cronbach's alpha $(\alpha=0.83)$.

Like previous findings this research result also come up with, care giving practices exposed caregivers to develop feelings of being stigmatized and excluded from different social capitals. Most of caregivers were exposed to high $\mathrm{n}=83(47.43 \%)$ and very high $\mathrm{n}=91(52 \%)$ stigma or social 
exclusion because of their care giving practices to their mentally ill family members. Stigma has far-reaching consequences that go beyond the stigmatized individual, affecting those closely associated with them. This is known as 'courtesy stigma' or 'stigma by association', [8].

Caregivers of people with mental illness have feeling of affiliate stigma as well as may experience stronger distress and perceive greater sense of burden in the care giving process, [37]. They may feel shameful for having family members with mental illness while obliged to take care of them. Thus, these caregivers may be subjected to feelings of strain and distress, as a result of their relationship with the discredited individuals and their care giving roles.

Family caregivers, who were living in Hong Kong with traditional Chinese culture [24], often shows lack of knowledge about mental illness such as the biological attribution of schizophrenia and are more concerned about stigma towards mental illness. When compared with Western countries, this misunderstanding of schizophrenia and other severe mental illnesses related to a faulty biological functioning, personal misconduct and spiritual beliefs and the resulting social stigma to the illness, may result in less favorable social support and more intense guilt feelings and burden in care giving for relatives with schizophrenia. The findings may have social implications, in that traditional cultural values and social stigma attached to mental illness is an issue of great concern for caregivers of people with mental illness.

Stigma is pervasive. It does not only affects individuals who carry the stigmatizing label, but also others who regularly associate with them, [6]. For individuals with mental illness, social support most often comes from family members who are active participants in their lives and who may themselves become targets for stigma, [31]. Thus, individuals who are stigmatized due to their association with mentally ill relatives this referred to as 'courtesy stigma' or 'stigma by association', [8]. For example, [37] family members of individuals with mental illness felt that they could not disassociate with the stigmatizing situation because they, themselves, were not only the 'marker' but also the 'marked'. By labeling their family member's disability, they became the 'marker', and by association to that family member, they were also 'marked' by society.

Generally, being a caregiver for mentally ill individuals expose caregivers to develop feeling of burden, psychological distress and feeling of stigmatization in the care giving experiences. Care giving [34] for mentally ill individuals expose caregivers to develop psychological distress, care giving burden and social exclusion or stigma. Participants in the interview explained that being a caregiver to mentally ill individual makes caregiver to have psychological distress, feeling of burden and stigma.

Participants in the interview were explained that as they feel unsure of how 'normal' people will identify or receive them and become constantly self-conscious and calculating about what impression they are making. Caregivers were often feeling as they are stigmatized or socially isolated because of the psychiatric illness. Families have to bear the major burden of care and this has resulted in an increase in the families' daily responsibilities and sources of stress at a time when they are also dealing with the uncertainty and stigma of chronic psychiatric illness in close relatives. Some ideas are directly taken from the participants during the interview.

Caregivers always feel inferiority due to their mentally ill relative; they feel that, people are considering them as and their mentally ill relatives are the only one who created for this disease. People in their neighbor's stigmatized them as not to have marriage relationship. This is because these people consider the disease is hereditary or genetically transfers. As a result they couldn't freely get marriage in their neighbor. In addition to this, caregivers never go to different social gatherings because; they consider people are talking at them due to the illness. They always embarrassed by the behavior of their patients when other friends are with them.

Table 3 and 4 signify that there is no statistically significant difference between gender regarding care giving burden and psychological distress $(\mathrm{t}=1.06, \mathrm{df}=173, \mathrm{p}>0.05$ and $\mathrm{t}=0.66, \mathrm{df}=173, \mathrm{p}>0.05)$ respectively. Having said this, being a male or female caregiver hasn't significant difference in developing care giving burden and distress. Even though, there is minimum score of sex mean difference on the dependent variables, it does not show significant or meaningful difference.

Similar to the current finding the association between mental disorder of caree and family subjective burden and distress appears to be similar in men and women. It does make sense that living with depressed persons may be associated with subjective burden and distress in the relatives regardless of their gender, [38]. However, some literatures indicated that more women than men tend to suffering from anxiety and depression due to their care giving practices,[38].

In contrast to the above finding, there exists sex difference in the strength of subjective burden and psychological distress of caregivers of people with mental illness, [38]. It is well established that women caregivers tend to suffer from depression to a greater extent than men, which may imply that they are more vulnerable to certain burdens and psychological distress but on the other hand, women also tend to have larger social networks and receive more social support, [38]. Some previous evidence shows that female spouses of mentally ill husbands tend to report greater levels of depression than vice versa, [38]. The impact of depressive illness on spouses of depressed patients; Journal of Cognitive Psychotherapy [39], however, one meta-analysis focusing predominately on dementia caregivers found small to very small gender differences in caregivers' social resources and health.

Table 5 and 6 shows, there is statistically significant difference between the types of disorder of patients in developing feeling of burden and distress on their caregivers $(\mathrm{t}=2.64, \quad \mathrm{df}=173, \quad \mathrm{p}<0.05$ and $\mathrm{t}=2.28, \quad \mathrm{df}=173, \quad \mathrm{p}<0.05)$ respectively. In short, caregivers of people with psychotic patients and caregivers of people with mood patients 
differently sense the burden and distress of care. In other word, the type of disorder that the patients have makes caregivers to experience burden and psychological distress differently.

Two studies have shown that the severity of illness of the patients increases the burden on the parents, [39]. Anxiety and depression disorders were not associated with very heavy burden or stress, and that this lends some support to previous results showing smaller burden associated with depressive disorders than schizophrenia, [39].

Table 8 and 9 shows that, caregivers' marital status does not make statistically significant mean difference in experiencing feeling of subjective burden and psychological distress on caregivers $(\mathrm{F}=0.34, \mathrm{df}=3, \mathrm{p}>0.05$ and $\mathrm{F}=1.16$, $\mathrm{df}=3, \mathrm{p}>0.05)$ in their order. This is to mean that, whether someone is married, single, divorced or widowed, it doesn't have significant difference in developing burden and psychological distress in his/her care giving experiences.

The differences in the number of divorces between the parents and the reference group could have had negative effect on the quality of life results. The results reported by Brown as early as in 1962 shows higher divorce rate when one person in the family was mentally ill, [40]. Accordingly, the situation of being a parent of mentally ill person could in itself have disruptive effect on the relationship between the parents. Female relatives of mentally ill persons were more distressed than[41] male relatives, although other findings also [39] reported there is no significant difference between female and male caregivers in developing psychological distress and subjective burden due to their care giving practices.

Table 13 indicates, there is no significant difference among caregivers level of education in developing care giving burden following to the service they provide to their patient $(\mathrm{F}=1.15, \mathrm{df}=3, \mathrm{p}>0.05)$. Educational level of caregivers as an independent variable doesn't have significant difference on caregivers to develop feeling of burden. Likewise, table 14 also shows, caregivers' educational level also does not bring statistically meaningful difference on caregivers psychological distress $(\mathrm{F}=0.068, \mathrm{df}=3, \mathrm{p}>0.05)$.

In contrast to the current study, educational level is a variable that can modulate the degree of burden and distress experienced by the relatives. In previous studies it has been found that the individuals with higher levels of education have less burden and distress, [39]. The caregivers who have low educational level have a mean burden of 93.52 $(\mathrm{SD}=9.82)$, while people with medium to high level of education have a mean score of $77.56(\mathrm{SD}=10.94)$. These difference is significant $(\mathrm{t}=4.913 ; \mathrm{p}<0.001)$. This is explained by the fact that these persons have higher knowledge of the disorder and of social resources that allow them to obtain better treatment for the patient and [15] the educational level of the caregiver would act as a "buffer" against the burden distress.

Table 17 indicates, the income level of caregivers does not show meaningful mean difference in creating feeling of burden on caregivers of people with mental illness $(F=0.93$, $\mathrm{df}=205.07, \mathrm{p}>0.05$ ).Furthermore, table 18 also shows, caregivers' income level hasn't significant mean difference in developing psychological distress on caregivers as a result of being associate or close relative to the patient $(\mathrm{F}=0.77, \mathrm{df}=4$, $\mathrm{p}>0.05)$. Generally, where ever caregivers placed on the different monthly income categories, it does not bring statistically significant mean difference on caregivers' subjective burden and psychological distress.

The loss of potential income of caregivers makes them to have burden and distress, [42]. However, in previous findings relatives who are employed out of home have a mean burden of $81.39(\mathrm{SD}=12.33)$ and careers who aren't employed have a mean of $90.52(\mathrm{SD}=12.25)$, differing significantly $(\mathrm{t}=)$ 2.362; $\mathrm{p}=0.02$ ). Anyway this economic potential of caregivers is insufficient for the subsistence of the patient. Though, the medicines and the medical attention are granted by the service of mental health institutions. This economic help continues being very scanty, considering all patients expenses (food, housing, gown, transportation). In addition, many mothers do not work out of the home, as consequence of the care giving, so they cannot contribute with any income and, must share this exiguous pension between two or more persons who live at home, [36].

Table 21 implies that there is no significant mean difference among the types of relationship with the patient in experiencing of subjective burden $(\mathrm{F}=1.43, \mathrm{df}=3, \mathrm{p}>0.05)$. It means, being a father, mother, sister/brother and other relationship with the patient does not have significant difference on caregivers' burden. Caregivers were more or less similarly sensing whatever the burden imposed from their patients. Table 22 also show the same result, the type of relationship that caregivers have with the patient does not show statistically significant mean difference in developing psychological distress on caregivers $(\mathrm{f}=0.37, \mathrm{df}=3, \mathrm{p}>0.05)$. Relatively speaking, caregivers equally feel for the psychological distress of care giving regardless of the relationship they have with the patient.

However, in most cases it is the mother who takes almost all responsibility for caring to the patient with mental illness. Parents (mainly mothers) have a mean burden of 90.16 $(\mathrm{SD}=11.99)$, the rest of caregivers have a mean of 73.56 $(\mathrm{SD}=6.52)$. These differences are significant $(\mathrm{t}=5.468$; $\mathrm{p}<0.001)$. Most studies show that the mother of the patient is the key career, [4]. The mother is the only person who feels her son's or daughter's problem as her own pain; as a result she is the only person who feels the highest burden and distress even if some family members share the problem in some extent,[42].

The correlation analyses reported in table 23 ensures that, there is significant and negative relationship between number of years on care giving and care giving burden of the participants $(\mathrm{r}=-0.205, \mathrm{P}<0.01)$.

There are studies that support the relationship between duration of illness of the patients and the distress or burden of the parents, [43]. There is no significant correlation between total quality of life of caregivers and their age, duration of illness of patients or functioning. Higher total 
burden correlated with severity of illness $(p<0.05)$, but there was no correlation between burden and duration of illness and functioning respectively.

Elderly parents were reported lower amount of burden and distress than do younger parents, and equivalently, parents who care for many years were reported lower amount of burden than do parents who have been given care for few years to the mentally ill relatives,[44]. However, other finding reported that, the older caregivers show higher burden than younger $(r=0.429 ; p=0.005)$. Patient's age also has an influence on the level of relatives' burden, while younger be the patient more burden to the caregivers $(\mathrm{r}=$ $0.309 ; \mathrm{p}=0.05),[45]$.

There is significant and positive correlation between affiliate stigma and care giving burden, affiliate stigma and psychological distress $(\mathrm{r}=0.34$ and $0.23, \mathrm{p}<0.01)$ respectively. The higher the caregivers' perceived stigma in care giving, the more severe their care giving burden and psychological distress it was. In addition to this, relatively high, positive and statistically significant relationship were computed between care giving burden and psychological distress $(r=0.34, p<0.01)$. This implies that, as care giving burden of the caregivers increases, their mental health problem also increase and vice versa. There is also significant negative relationship between time spent on care giving and care giving burden $(\mathrm{r}=-0.21, \mathrm{p}<0.01)$. In contrast other variables which are reported in table 10 haven't any significant relationship.

Elderly parents were reported lower amount of burden and distress than do younger parents, and equivalently, parents who care for many years were reported lower amount of burden than do parents who have been given care for few years to their mentally ill relatives, [44]. Caregivers who feel as they are stigmatized by the society, tends to develop feeling of burden and psychological distress or low level of functioning, [46]. The youngest group of caregivers had significantly lower values in overall quality of life, more stressful and have unstable social life situation than the older parents of patients with mental illness, [47].

Affiliate stigma was found to [48] serve as a predictor for caregivers' subjective burden and psychological distress $\left(\mathrm{r}^{2}=\right.$ $0.44,19.36 \%, \mathrm{P}<0.01)$ and $\quad\left(\mathrm{r}^{2}=0.42,17.64 \%, \mathrm{p}<0.01\right)$ respectively. Similar to this finding, the current finding also found the same result.

As shown in table 25, 5.4\% of psychological distress of respondents were found to be because of affiliate stigma $\left(\mathrm{r}=0.23, \mathrm{r}^{2}=0.054\right.$ or $\left.5.4 \%, \mathrm{p}<0.05\right)$. In other word, affiliate stigma predicts $5.4 \%$ of psychological distress of participants. Affiliate stigma $(\mathrm{M}=4.52, \mathrm{SD}=0.67)$ was significantly correlated with psychological distress $(\mathrm{M}=2.95, \mathrm{SD}=0.71$; $\mathrm{r}=0.28, \mathrm{P}<0.01)$ and subjective burden $(\mathrm{M}=2.90, \mathrm{SD}=$ $0.73 ; \mathrm{r}=0.33, \mathrm{P}<0.01),[21]$. Regression analyses were conducted to see the predictive power of demographic variables for psychological distress and subjective burden. None of the demographic variables were significantly related to psychological distress and subjective burden, [21].

Subjective burden explained 11 and $9 \%$ of variance in psychological distress and affiliate stigma, respectively. When affiliate stigma was entered into the regressions, it further explained 9 and $33 \%$ of variance in psychological distress and subjective burden, respectively, [43]. Whereas subjective burden continued to be significantly related to psychological distress after affiliate stigma was entered into the equation, [19]. Caregivers' burden was significantly related to psychological distress: $\mathrm{R} 2=0.57, \mathrm{~F}(3,25)=11.08$, $\mathrm{P}<0.001$.

In the current study which is demonstrated in table 24, $11.60 \%$ of psychological distress of participants were found to be due to the care giving burden $\left(r=0.34, r^{2}=0.116\right.$ or $11.60 \%, \mathrm{p}<0.05)$. This is to mean, care giving burden predicts $11.60 \%$ of psychological distress.

Affiliate stigma was significantly [49] related to psychological distress $(\mathrm{b}=0.34, \mathrm{P}<0.01)$ and subjective burden $(\mathrm{b}=.67, \mathrm{P}<0.001)$. Affiliate stigma had been added to the equation were 0.10 for psychological distress and 0.22 for subjective burden, both of which suggested mediating role of affiliate stigma, [50].

\section{Conclusions}

Many patients with mental illness rely on their relatives for emotional support, instrumental and economic assistance. Families of people with mental illness often provide considerable support to their ill relatives and experience important level of burden and distress as result. Demands of care giving include paying for psychiatric treatment, supervision of the patient, dealing with societal stigma associated with mental illness, and emotional distress that may result from symptoms of family member's disorder. Caregivers develop psychological state that results from the combination of the physical work, emotional and social pressure, like the economic restriction that arises of taking care of the patients. Burden of care is associated with reduced quality of life and significant impacts on the health and functioning of caregivers. The key caregiver is seen as the person who provides the most support to the patient and often devoting substantial numbers of hours each day.

\section{Acknowledgments}

This study is taken from my MSc thesis that I had conducted for the partial fulfillment of my Masters Degree in Clinical Psychology from University of Gondar. For this reason, it is my pleasure to acknowledge the contributions of my advisor, friends and family relatives for the fulfillment of this research work. First and for most I would like to express my heartfelt gratitude to my advisor Dr. Alan Krohn an Associate Professor in the University of Michigan, America for his unreserved effort and commitments in giving constructive comments and encouragement. In line with this, I would like to acknowledge Mr. Misaye Mulatie who helped me in giving constructive comments regularly for the accomplishment of my thesis. In addition to this, I would like to express my heartfelt gratitude to Mr. Bisrat Tekle who 
helped me materially and through constructive suggestions. It is my pleasure also to acknowledge all my classmates who helped me in giving constructive comments and showing directions in my work. Lastly but not least, I would like to say thanks for my family members who contributed their own role for the fulfillment of this research work.

\section{Reference}

[1] World Health Organization. (2003). World health ministers a call for action to mental health. Geneva.

[2] Thomas and Robert, (2001).Abnormal psychology: University of Virginia.

[3] Uba L. (1994) Asian Americans: Personality Patterns, Identity, and Mental Health. Guilford Press, New York.

[4] Bloch, S., Szmukler, G., Herrman, H., Benson, A., and Colussa, S., (1995). Counseling caregivers of relatives with schizophrenia: Themes, interventions, and caveats. Family Process.

[5] Gutie'rrez J, Caqueo A, Kavanagh D. Burden of care and general health in families of patients with schizophrenia. Social Psychiatry and Psychiatric Epidemiology (in press) 2005.

[6] Östman, M. \& Kjellin, L. (2002) Stigma by association: psychological factors in relatives of people with mental illness. British Journal of Psychiatry.

[7] Shu B. C. \& Lung R. W. (2005). The effect of support group on the mental health and quality of life for mothers with autistic children. Journal of Intellectual Disability Research.

[8] Rush, L. L., (2010). Affective reactions to multiple social stigmas. Journal of Social Psychology.

[9] Garretero S, Garce's J, Ro'denas F, Sanjose' V (2009). The informal caregivers' burden of dependent people: theory and empirical review. Arch Gerontol Geriatr.

[10] Mwinituo P. P. \& Mill J. E. (2006) Stigma associated with Ghanaian caregivers of AIDS patients. Western Journal of Nursing Research.

[11] Maurin, J. T., \& Boyd, C. B. (1990). Burden of mental illness on the family: A critical review. Archives of Psychiatric Nursing.

[12] Potasznik, H., \& Nelson, G. (1984). Stress and social support: The burden experienced by the family of a mentally ill person. American Journal of Community Psychology.

[13] Green S. E. (2007). "What do you mean 'what's wrong with her?": Stigma and the lives of families of children with disabilities. Social Science \& Medicine.

[14] Perring, C, Twigg, J., \& Atkin, K. (1990). Families caring for people diagnosed as mentally ill: The literature re-examined. London, U.K.: HMSO.

[15] Pickett, S.A., Cook, J.A., Cohler, F.J., \& Solomon, M.L. (1997). Positive parent-adult child relationships: Impact of severe mental illness and care giving burden. American Journal of Orthopsychiatry.

[16] Cook, J. A., Lefley, H. P., Pickett, S., \& Cohler, B. J. (1994).
Age and family burden among parents of offspring with severe mental illness. American Journal of Orthopsychiatry

[17] Aronson, J. (1992). Women's sense of responsibility for the care of old people: "But who else is going to do it?" Gender \& Society, 6, 8-29.

[18] Stanley Medical Research funded Studies of Schizophrenia and Bipolar Disorders. (1997-2006). Health System Review Report. Federal Republic of Ethiopia, Ministry of Health: Amanuel Psychiatric Hospital.

[19] Corrigan P. W. \& Penn D. L. (1999). Lessons from social psychology on discrediting psychiatric stigma. American Psychologist.

[20] Link B. G. \& Phelan J. C. (2001) Conceptualizing stigma. Annual Review of Sociology.

[21] Fadden G., Bebbington P. \& Kuipers L. (1987). Caring and its burdens: a study of the spouses of depressed patients. British Journal of Psychiatry.

[22] Greenberg J. S., Seltzer M. M. \& Greenley J. R. (1993) Aging parents of adults with disabilities: the gratifications and frustrations of later-life care giving. Gerontologist.

[23] Green S. E. (2003, 2007). "What do you mean 'what's wrong with her?": Stigma and the lives of families of children with disabilities. Social Science \& Medicine.

[24] Mak W. W. S. \& Chen S. X. (2006) Face concern: its role on stress-distress relationships among Chinese Americans. Personality and Individual Differences.

[25] Bambauer K. Z. \& Prigerson H. G. (2006). The stigma receptivity scale and its association with mental health service use among bereaved older adults. The Journal of Nervous and Mental Disease.

[26] Phelan, J. C., Bromet, E. J., \& Link, B. G. (1998). Psychiatric illness and family stigma. Schizophrenia Bulletin.

[27] Schofield H, ed: Family Caregivers: Disability, Illness and Ageing. St Leonards, NSW: Allen and Unwin; 1998.

[28] Hochschild AR: The Managed Heart. Berkeley, CA: University of California Press; 1983.

[29] Rush, L. L., (1998). Affective reactions to multiple social stigmas. Journal of Social Psychology.

[30] Chafetz, L. and Barnes, L. (1989). Issues in psychiatric caregiving: Archives of Psychiatric Nursing.

[31] Lefley, H. (1992). Expressed emotion: conceptual, clinical and social policy issues. Hospital and Community Psychiatry.

[32] Butzlaff RL, Hooley JM (1998). Expressed emotion and psychiatric relapse: a meta analysis. Arch Gen Psychiatry.

[33] Choi S. C. \& Lee S. J. (2002) Two-component model of chemyon-oriented behaviors in Korea: constructive and defensive chemyon. Journal of Cross-Cultural Psychology.

[34] Novak M. \& Guest C. (1989) Application of a multidimensional caregiver burden inventory.

[35] Wahl, O. F. \& Harman, C. R. (1989). Family views of stigma. Schizophrenia Bulletin.

[36] Kuipers L, Leff J, Lam D (1992) Family work for schizophrenia: a practical guide. Gastell, London. 
[37] Chung, K.F. \& Wong, M.C. (2004).Experience of stigma among Chinese mental health patients in Hong Kong. Psychiatric Bulletin.

[38] Dunst CJ, Trivette CM, and Cross AH: Mediating influences of social support: personal, family and child outcomes. Am J Ment Defic1986.

[39] King G, King S, Rosenbaum P, goffin R: Family-centered care giving and well-being of parents of children with disabilities: Linking process with outcome. Journal of pediatric psychology 1999.

[40] Phelan J. C. (2001) Conceptualizing stigma. Annual Review of Sociology.

[41] Watson A. C. (2002). The paradox of self stigma and mental illness. Clinical Psychology: Science and Practice.

[42] Jahoda A. \& Markova I. (2004). Coping with social stigma: people with intellectual disability moving from institutions and family home. Journal of Intellectual Disability Research.

[43] Dyck DG, Short R, Vitaliano PP (1999). Predictors of burden and infectious illness in schizophrenia caregivers. Psychosom Med.
[44] Colder, B. J., Pickett, S. A., \& Cook, J. A. (1991). The psychiatric patient grows older: Issues in family care. In E. Light \& B. Lebowitz (Eds.). The elderly with chronic mental illness: Directions for research. New York: Springer.

[45] Pachankis J. E. (2007). The psychological implications of concealing a stigma: a cognitive affective-behavioral model. Psychological Bulletin.

[46] Tedla W. Giorgis. (2000). The Last Taboo: Breaking the Silence about Depression and Mental Illness. JEBDU: SELEDA Ethiopia.

[47] Caqueo A, Kavanagh D. Burden of care and general health in families of patients with schizophrenia. Social Psychiatry and Psychiatric Epidemiology (in press) 2005.

[48] Damrosh, S. P. \& Perry, L. A. (1989). Self reported adjustment, chronic sorrow, and coping with parents of children with Down syndrome. Nursing Research.

[49] Fink, P. J. \& Tasman, A. (1992). Stigma and Mental Illness. Washington, DC: American Psychiatric Press.

[50] Corrigan P. W. \& Watson A. C. (2002). The paradox of self stigma and mental illness. Clinical Psychology: Science and Practice 